\title{
The Origin of Ovarian Cancer Species and Precancerous Landscape
}

\author{
Ie-Ming Shih, ${ }^{*}{ }^{\dagger}$ Yeh Wang, ${ }^{\dagger}$ and Tian-Li Wang ${ }^{* \dagger}$
}

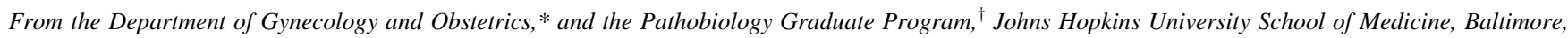
Maryland

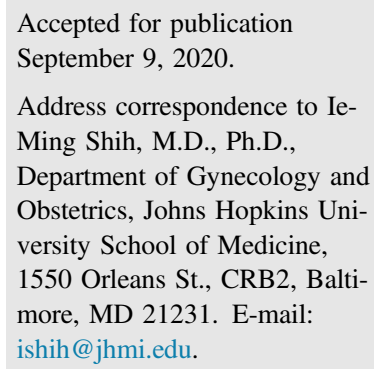

\begin{abstract}
Unlike other human cancers, in which all primary tumors arise de novo, ovarian epithelial cancers are primarily imported from either endometrial or fallopian tube epithelium. The prevailing paradigm in the genesis of high-grade serous carcinoma (HGSC), the most common ovarian cancer, posits to its development in fallopian tubes through stepwise tumor progression. Recent progress has been made not only in gathering terabytes of omics data but also in detailing the histologic-molecular correlations required for looking into, and making sense of, the tissue origin of HGSC. This emerging paradigm is changing many facets of ovarian cancer research and routine gynecology practice. The precancerous landscape in fallopian tubes contains multiple concurrent precursor lesions, including serous tubal intraepithelial carcinoma (STIC), with genetic heterogeneity providing a platform for HGSC evolution. Mathematical models imply that a prolonged time (decades) elapses from the development of a TP53 mutation, the earliest known molecular alteration, to an STIC, followed by a shorter span (6 years) for progression to an HGSC. Genetic predisposition accelerates the trajectory. This timeline may allow for the early diagnosis of HGSC and STIC, followed by intent-to-cure surgery. This review discusses the recent advances in this tubal paradigm and its biological and clinical implications, alongside the promise and challenge of studying STIC and other precancerous lesions of HGSC. (Am J Pathol 2021, 191: 26-39; https://doi.org/10.1016/j.ajpath.2020.09.006)
\end{abstract}

Elucidating the pathogenesis in early cancer development is fundamental in identifying biomarkers for early detection and for the exploration of cost-effective strategies of cancer prevention. This task represents an unmet need in cancers that are not amenable to routine cancer screening or primary prevention. Ovarian cancer is one such example-the malignancy is located deep in the pelvis, is not readily detected clinically, and is highly fatal. Currently, there are few effective approaches to intercepting its progression from a noninvasive precursor stage to an advanced, incurable stage.

The study of the early progression of ovarian cancer is confounded by the fact that ovarian cancer is a constellation of various neoplasms rather than being a single disease, notwithstanding the fact that almost all ovarian epithelial cancers are developmentally related to the Müllerian duct, an anlage of female reproductive tract components including fallopian tubes, uterus, the uterine cervix, and the superior portion of the vagina. Ovarian carcinomas are conventionally classified according to histologic subtype, and each subtype is characterized by distinct clinicopathologic and molecular features as well as tissue of origin (Figure 1). For simplicity, ovarian carcinomas can be broadly classified as type 1 or $2 .{ }^{1,2}$ Type 1 carcinomas include clear cell, endometrioid, mucinous, and low-grade serous carcinomas, whereas type 2 carcinomas mainly comprise high-grade serous carcinomas (HGSCs). Type 2 ovarian cancers are distinguishable from type 1 neoplasms

Supported by NIH/NCI grants P50CA228299 (I.-M.S.), RO1CA215483 (I.-M.S.), and UO1CA200469 (I.-M.S.); Department of Defense Ovarian Cancer Research Program grant W81XWH-19-1-0232 (I.-M.S.); the Tina Brozman Foundation (I.-M.S.); the Ovarian Cancer Research Alliance (I.-M.S.); and Johns Hopkins University Department of Gynecology and Obstetrics Richard W. TeLinde Endowment (I.-M.S.).

Disclosures: None declared. 


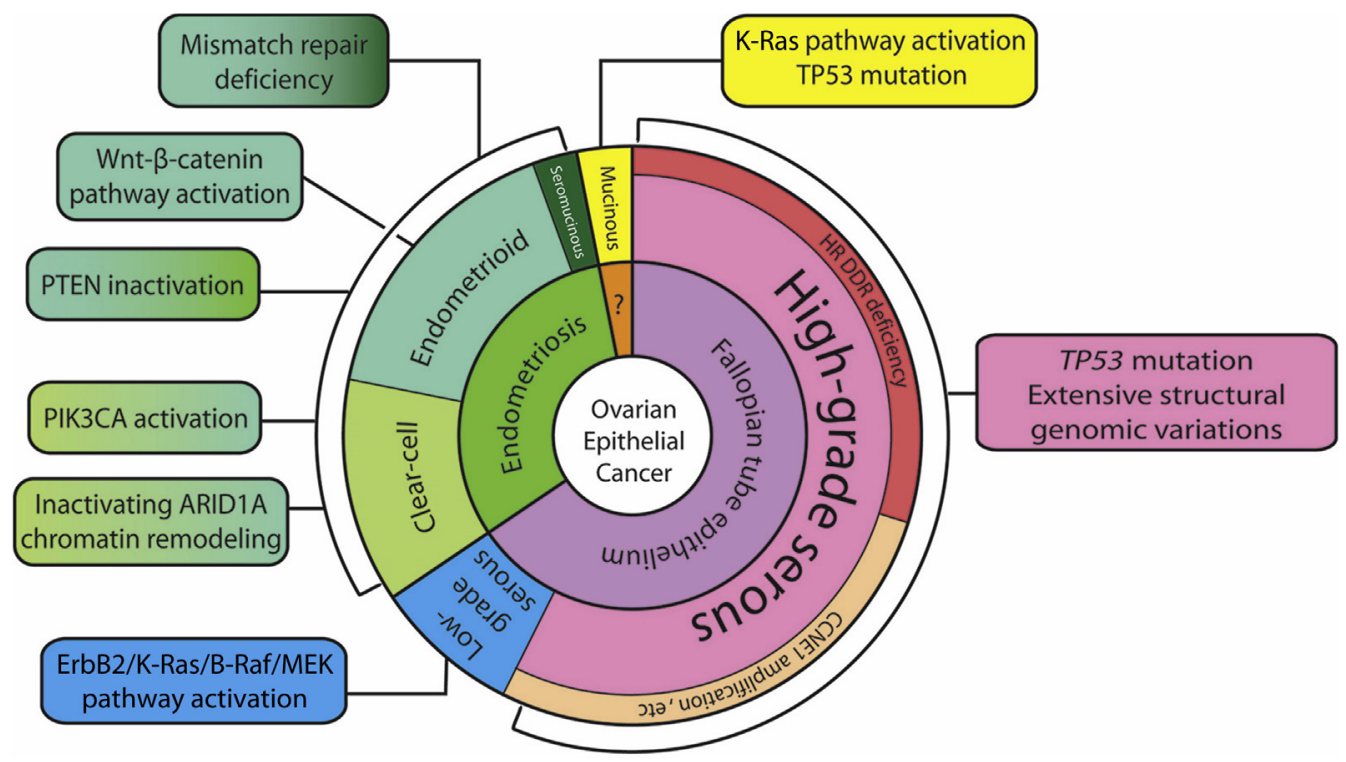

Figure 1 The tissue origins and major molecular pathway alterations in different types of ovarian epithelial cancer. ARID, AT-rich interactive domaincontaining protein; CCNE, G1/S-specific cyclin-E; ErbB, extracellular region binding protein; HR DDR, homologous recombination DNA damage repair; MEK (alias mitogen-activated protein kinase, MAPK); PIK3CA, phosphatidylinositol 3-kinase catalytic subunit $\alpha$; PTEN, phosphatase and tensin homologue.

by several features: i) more frequent high-stage disease at diagnosis, ii) universal TP53 mutations, iii) either a defective homologous recombination DNA repair pathway or amplification of $C C N E 1$, and iv) uncommon mutations in genes involving mismatch DNA repair and in the AT-rich interactive domain-containing protein (ARID1A), phosphatidylinositol 3-kinase (PI3K), K-Ras/B-Raf, Wnt, and protein phosphatase 2A pathways. ${ }^{3,4}$ HGSCs are the most common type of epithelial ovarian cancer and are the primary focus of this review (Figure 1).

The tissue origin of HGSC has eluded investigators for decades, given that attempts to demonstrate its ovarian origin were mostly unsuccessful. Kuhn and Hacking ${ }^{5}$ felt that a crisis of confidence occurs when puzzles arise that

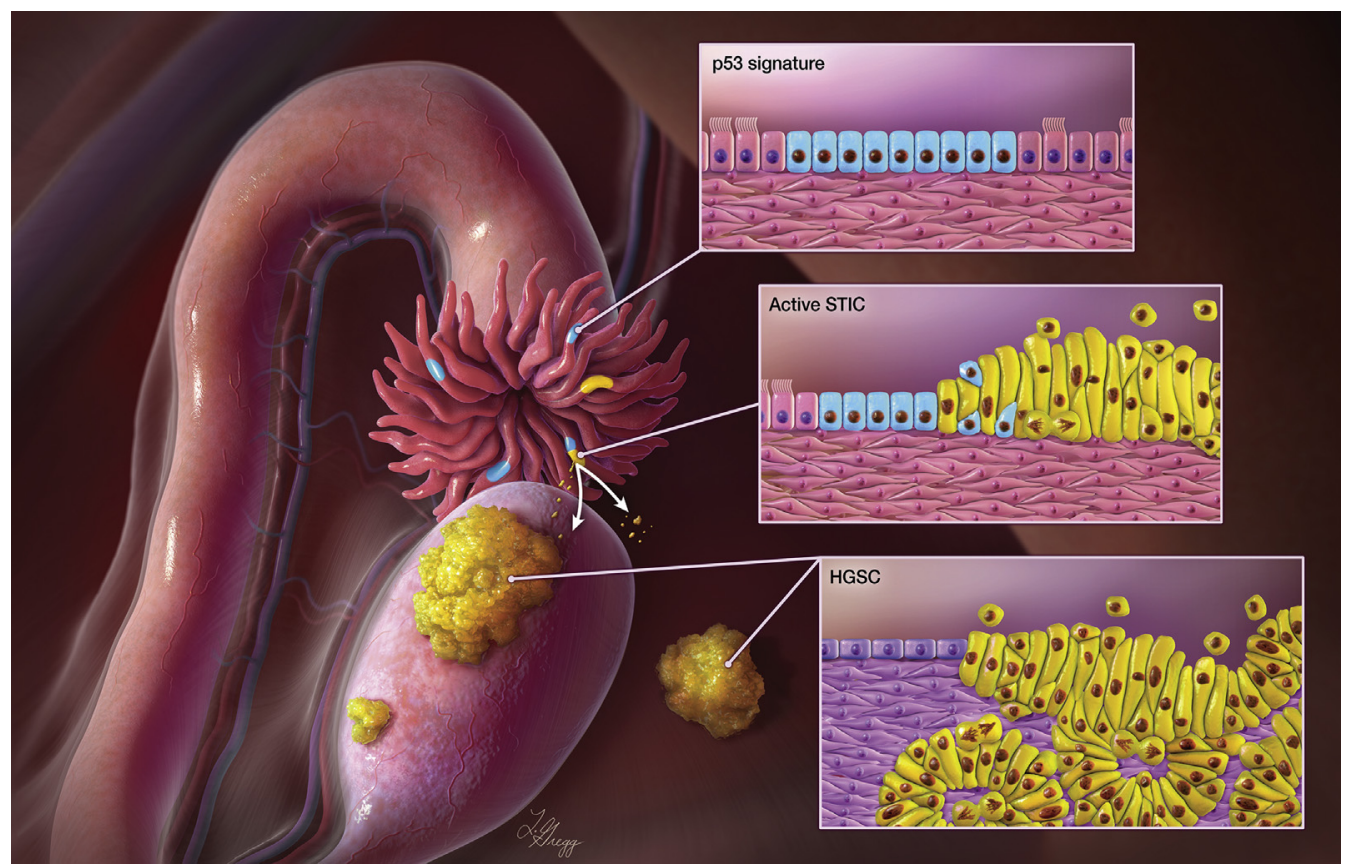

Figure 2 Paradigm of fallopian tube as the origin of high-grade serous carcinomas (HGSCs). Multiple fallopian tube lesions including serous tubal intraepithelial carcinoma (STIC) (yellow lines in the fimbriated end) and p53 signature (blue lines) can occur at the fimbriated end. STIC is presumed to be the immediate precursor of HGSC. STIC cells can become invasive in the fallopian tube, and detach from the fallopian tube surface, spreading onto the peritoneal surface, enclosing ovary, bowel, peritoneal wall, and omentum. Natural selection favors emigrated STIC cells that can survive and reproduce within a certain tissue-environmental niche which grow into tumor nodules and cause tumor ascites. Illustration by Lydia Gredd, M.A., C.M.I., @ 2020 I. Shih at JHU; used with permission. 
repeatedly resist solutions. During a crisis, the paradigm is subjected to testing and might be rejected. Here, the crisis of confidence is whether epithelial ovarian cancer indeed arises from the ovary. It has become increasingly clear in recent years that many HGSCs develop from the epithelial precursor lesions on the fallopian tubes rather than from the ovary, which, in humans, is largely devoid of Müllerian epithelium. This new paradigm of ovarian cancer genesis was based on the original observation of dysplastic epithelium in the fallopian tube in women carrying BRCAl and $B R C A 2$ germline mutations. ${ }^{6-8}$ Serous tubal intraepithelial carcinoma (STIC) is the immediate precursor of HGSC. STIC is characterized by a continuation of nonciliated tubal epithelial cells showing marked nuclear atypia, mitotic figures, apoptotic bodies, loss of cellular polarization, a p53 staining abnormality (pattern compatible with either missense or deletion mutations), and an increased Ki-67 labeling index ${ }^{8-12}$ (Figure 2). The tubal paradigm proposes that STIC formation precedes HGSC, and that the STIC can become invasive into the underlying tubal mucosa, and, more often, that the STIC cells can detach from the fallopian tube surface and spread directly onto the peritoneal surface enclosing ovary, bowel, peritoneal wall, and omentum. Natural selection equips the emigrated STIC cells to survive and reproduce within certain tissue environmental niches to grow tumor nodules and cause tumor ascites (Figure 2). Because of proximity to the fimbriated ends of fallopian tubes and friendly environment (enriched blood supply as an example), ovaries are usually the first stop for STIC cells to arrive and develop into an ovarian HGSC. However, STIC cells or tubal epithelium with early serous proliferation may bypass ovarian tissues and lodge into peritoneal surface or omentum to form the peritoneal primary HGSC. ${ }^{13}$

In addition to STIC, the p53 signature is another lesion on fallopian tube epithelium; it is defined by a small stretch of 10 to 30 normal-appearing epithelial cells with an intense p53 immunostaining pattern compatible with a missense TP53 mutation. ${ }^{14-16}$ Sequencing results have confirmed such mutations in all p53 signatures analyzed. ${ }^{17-19}$ p53 Signature lesions are morphologically indistinguishable from the adjacent TP53 wild-type epithelium by hematoxylin and eosin staining, and can be detected only by p53 immunostaining.

\section{Evidence Favoring the Tubal Paradigm}

A wealth of epidemiologic, clinical, pathologic, and molecular studies support the tubal paradigm. Epidemiologically, STIC has been much more frequently detected in women at increased risk for HGSC than in those at average risk. ${ }^{20}$ In a multicenter study, by extensive examination of surgically removed fallopian tubes, STIC and p53 signatures were detected in $10 \%$ and $27 \%$ of fallopian tubes from BRCA1/2 carriers undergoing prophylactic salpingo-oophorectomy, respectively. ${ }^{20}$ In contrast, tubal lesions have been reported as uncommon $(<0.1 \%)$ in women without pathogenic germline mutations in $B R C A 1 / 2$ or other homologous recombination genes. As many as $60 \%$ of HGSCs are associated with STICs, ${ }^{8,21}$ and this phenomenon is rare in type 1 ovarian cancers. Transcriptomic analysis demonstrates that HGSCs resemble fallopian tube epithelium at a molecular level as compared to ovarian surface epithelium or peritoneal mesothelium. ${ }^{22,23}$ A recent study further applied singlecell transcriptome analysis on individual fallopian tube epithelial cells in women without cancer. ${ }^{24}$ The investigators identified five major fallopian tube epithelial cell subtypes. The subtype signatures could be identified in HGSCs, but exhibited high intratumor heterogeneity. Molecular genetic studies indicate that the total number of somatic mutations and loss of heterozygosity events increase from p53 signature, STIC, and HGSC, a finding compatible with a model of progressive tumor development. ${ }^{17}$ Importantly, where tissues have been available for analysis, many STICs have been reported to harbor the same TP53 mutations as the concurrent HGSCs. ${ }^{25}$ Based on comparisons of the molecular genetic alterations in precursor lesions and HGSCs, reconstruction of phylogeny suggests that STIC is the precursor of many HGSCs from the same cases, albeit with a complex relationship. ${ }^{17-19}$ The findings from those studies have also suggested that some p53 signatures may precede STIC as the earliest recognizable precursor lesion. Incidental STICs without a synchronous HGSC have also shown molecular alterations similar to those in STICs associated with HGSC. ${ }^{17}$ As compared to the associated HGSC, many of the STICs have shorter telomeres, ${ }^{26,27}$ an observation that has also been reported in precursor lesions of many cancer types, supporting STIC as the precursor of HGSC. More recently, the methylation profile of STIC was demonstrated as more similar to that of the associated HGSC compared to that of adjacent fallopian tube epithelium. ${ }^{28,29}$ Lastly, STIC-like lesions have been found in genetically engineered mouse models carrying oncogenes driven by either oviduct glycoprotein-1 or paired box protein (PAX)-8; these mice eventually developed carcinoma that invaded the ovaries. ${ }^{30,31}$

\section{Precancerous Landscape in the Fallopian Tube}

It is not possible to portray the landscape and reconstruct evolution history in HGSC development without a detailed histologic examination and molecular genetic analysis of normal fallopian tube and tubal precursor lesions before the development of cancer. In hindsight, most prior studies analyzed HGSCs and precursor lesions from the same cases, raising a concern that the voluminous invasive carcinoma may have effaced and destroyed the natural habitats of possible precursor lesions in the fallopian tube. 
The first recognizable feature of the precancerous landscape is the loss of ciliated cells on tubal epithelium. In normal fallopian tubes, both secretory and ciliated epithelial cells constitute the fallopian tube epithelium, and the ratio of secretory to ciliated cells increases by age, likely due to a decrease in estradiol levels, and in specimens obtained from women at high risk for HGSC. ${ }^{15,32,33}$ The increased density of secretory cells can be the result of secretory cell expansion or overgrowth, as manifested by a small patch of contiguous normal-appearing secretory cells. Because p53 signatures, STIC, and HGSC are all nonciliated, these cells are at least ostensibly qualified to become candidates of tubal lesions. However, whether these regions of secretory cell expansion or overgrowth are ever clonal or can initiate STIC is uncertain. The second recognizable feature is the presence of multiple clonally derived tubal lesions, including STIC and p53 signatures from the same individual (Figure 2). In a multicenter study, approximately half of $>100$ prophylactic salpingectomy specimens examined had multiple incidental STIC and/or p53 signature lesions. ${ }^{20}$ In contrast, multiple lesions are uncommon in tubal specimens invaded by HGSC, most likely because those minute precursors can be readily replaced by the bulk of carcinoma.

Are these multiple lesions clonally related? Analysis of somatic mutations including TP53 and DNA copy number alterations demonstrate that the majority of precursor tubal
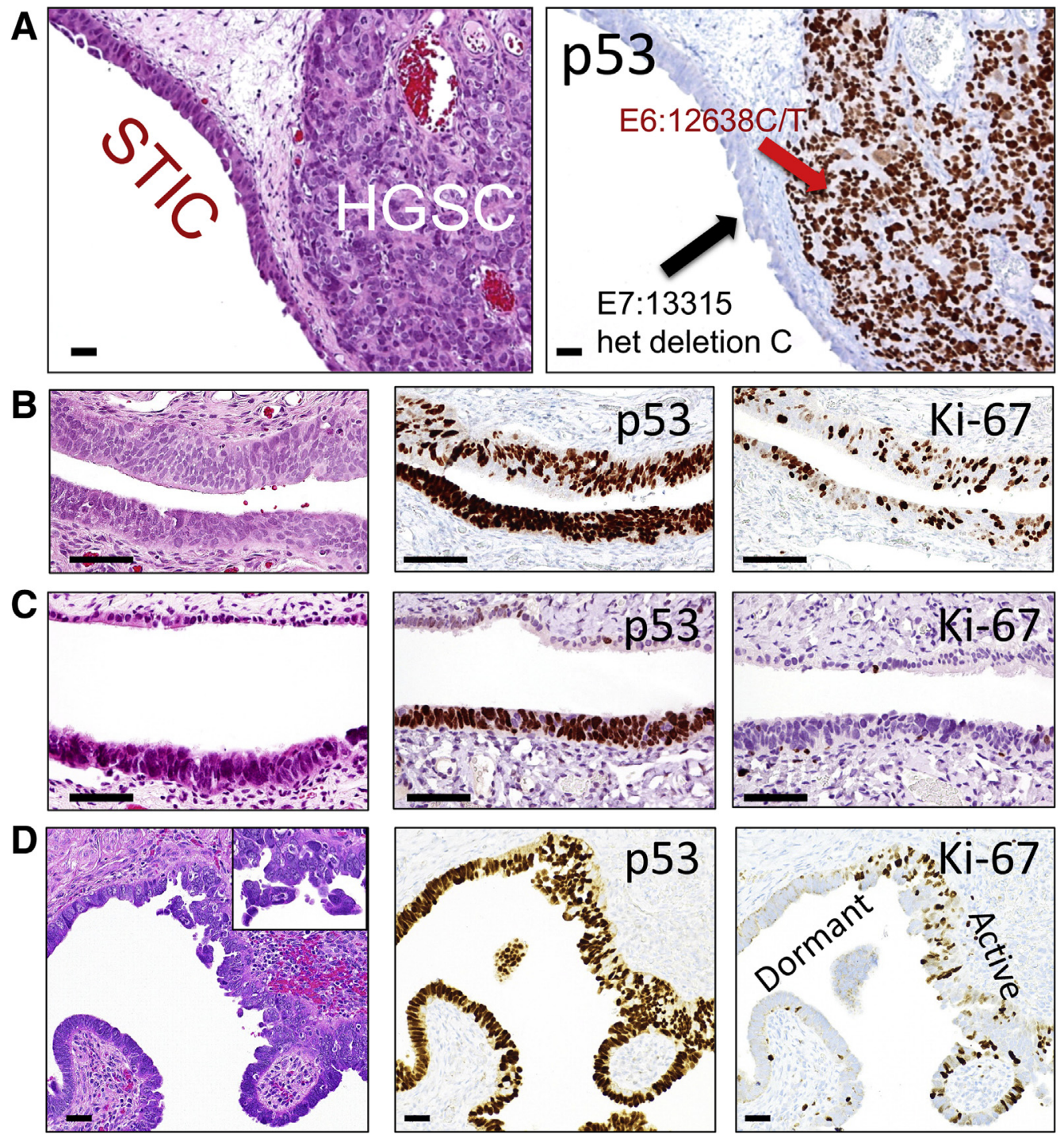

Figure 3 Examples of serous tubal intraepithelial carcinoma (STIC) and high-grade serous carcinoma (HGSC). A: A STIC is closely associated with an invasive HGSC. Both lesions contain different TP53 mutations, suggesting that the HGSC is clonally independent of the STIC. B: An example of STIC with an intense and diffuse p53 staining pattern compatible with a missense TP53 mutation and a high proliferative activity as indicated by Ki-67-labeled epithelial cells. C: A dormant STIC with a TP53 mutation staining pattern of a very low proliferative activity. D: Another example of a STIC showing both proliferation active and dormant STIC areas. Hematoxylin and eosin stain sections of B, C, and $\mathbf{D}$ are shown in the left panels. The inset in D shows loose clusters of STIC cells detaching from the tubal surface. Scale bars $=100 \mu \mathrm{m}(\mathbf{A}-\mathbf{D})$. Original magnification, $\times 20$ (inset). 
lesions from individual women were clonally independent. ${ }^{34}$ Similarly, based on observations of clonal heterogeneity in ovarian HGSCs, Bashashati et $\mathrm{al}^{35}$ proposed the existence of a polyphyletic clonal development track at a very early stage of tumor evolution. Whether these multiple tumor-initiating clones occur at a similar time frame due to a field carcinogenic effect, or appear sequentially over time, is unclear.

The findings of multi-clonality suggest a complex phylogenesis in the development of multiple precursor lesions prior to HGSC development. ${ }^{17}$ A parallel clonal trajectory involving multiple precursor lesions contrasts with the linear progression model from STIC to HGSC, as previously suggested. ${ }^{18,19}$ It is plausible that one of the multiple STICs may expand further and outgrow other coexisting precursors, ultimately progressing to an HGSC that quickly effaces normal-appearing fallopian tube tissues including other precursor lesions. In this case, some of the extant STICs or p53 signatures in the fallopian tubes removed together with the HGSC may represent close "cousins" akin to the STIC that originally gave birth to the HGSC. This explanation can well accommodate the discrepancies in previous molecular genetic studies that have compared mutation profiles between a STIC and a concurrent HGSC, or in p53 immunostaining studies that have shown discordant staining patterns between a STIC and an adjacent HGSC $^{25}$ (Figure 3A). For example, one study reported that 4 of 29 women with concurrent ovarian/pelvic HGSC and STIC lesions harbored nonidentical TP53 mutations, indicating clonal independence. ${ }^{25}$ This view does not refute that the HGSC does not originate from a STIC. Rather, it indicates that the observed genuine precursors from which HGSCs develop may not be as common as thought, because of the preponderant growth of HGSCs destroying their neighboring minute precursors, a task that is normally perfomed by highly aggressive malignant tumors. Thus, the same founder mutations (eg, in TP53) and a similar somatic mutation profile found in both a putative STIC and the synchronous HGSC deserve careful interpretation to rule out the possibility that the STIC is actually an intratubal metastasis from the bulk of the established HGSC. ${ }^{19}$

Analyzing proliferative activity in tubal precursor lesions can also yield informative insights. The proliferation index, as assessed by the percentages of Ki-67-positive cells, usually varies significantly in STICs. In the preliminary analysis, most STICs have a much higher proliferative activity as compared to background normal epithelium, but approximately $20 \%$ to $30 \%$ of STICs, like p53 signatures, have a background level of Ki-67 labeling similar to that in normal-appearing fallopian tube epithelial cells (Figure 3, B-D). The term dormant STICs is proposed for STICs with a background Ki-67 index. Whether these STICs remain biologically dormant, and thus represent an evolutionary dead end, or whether they can regain proliferation to wake up as an HGSC is an interesting question, not only from the perspective of tumor biology, but also from the standpoint of clinical management. The molecular mechanisms of these lesions staying in an inert and quiescent state remain speculative, but they may be the result of telomere shortening and oncogene-induced cellular senescence (Tumor Initiation and Evolutionary Trajectory).

\section{Tumor Initiation and Evolutionary Trajectory}

The molecular events in initiating HGSC development may involve both epithelial cells and their microenvironment, including stroma and immune cells. The molecular alterations that potentially contribute to tumor progression are summarized in Figure 4. The incessant ovulation theory for HGSC carcinogenesis has received much attention because of consistent observations that the number of lifetime ovulations is positively related to ovarian cancer incidence. ${ }^{36}$ The fluid ruptured from follicles during ovulation is proposed to be carcinogenic because it contains abundant free radicals, reactive oxygen species, and other genotoxic substances, which can damage DNA, break DNA strands, and initiate DNA damage repair. ${ }^{37}$ The fallopian tube epithelial cells, especially those located at the fimbriated ends where most of the STICs are found, are directly exposed to follicular fluids immediately after ovulation. With repeated episodes of DNA damage and repair, the follicular fluid-bathed tubal epithelial (putative progenitor) cells may acquire somatic mutations and epigenetic changes, some of which are cancer promoting, and expand clonally. This carcinogenic process accelerates in the presence of germline mutations and epigenetic inactivation of genes involved in homologous recombination DNA repair, such as BRCA1 and BRCA2. Furthermore, insulin growth factor (IGF) in follicular fluid promotes the transformation of TP53-mutated epithelial cells. ${ }^{38}$

It may not be possible to understand how HGSCs evolve from fallopian tube epithelium or to deduce a timeline from tumor initiation and progression without delineating the first possible clonal event in normal epithelium. In light of universal TP53 mutations in STICs and HGSCs, ${ }^{17,25,39}$ a p53 signature, as its name suggests (abnormal p53 staining due to a TP53 mutation, the first "hit"), may be the earliest recognizable lesion that precedes STIC. However, a p53 signature may reflect a nonmalignant clonal expansion from a tubal progenitor cell that acquires TP53 mutations as a stochastic event. Thus, the intense p53 staining that reflects a missense TP53 mutation becomes a surrogate marker for visualizing this clonal patch of epithelial cells on tissue sections. If a $\mathrm{p} 53$ signature progresses to a STIC, then one would expect to observe a p53-STIC joint lesion, albeit uncommonly; but such evidence is still lacking. Perhaps there are numerous such benign, clonally derived, epithelial cells forming small clusters throughout the fallopian tube that cannot be detected. This is supported by the agingrelated clonal expansion of progenitor cells derived from 


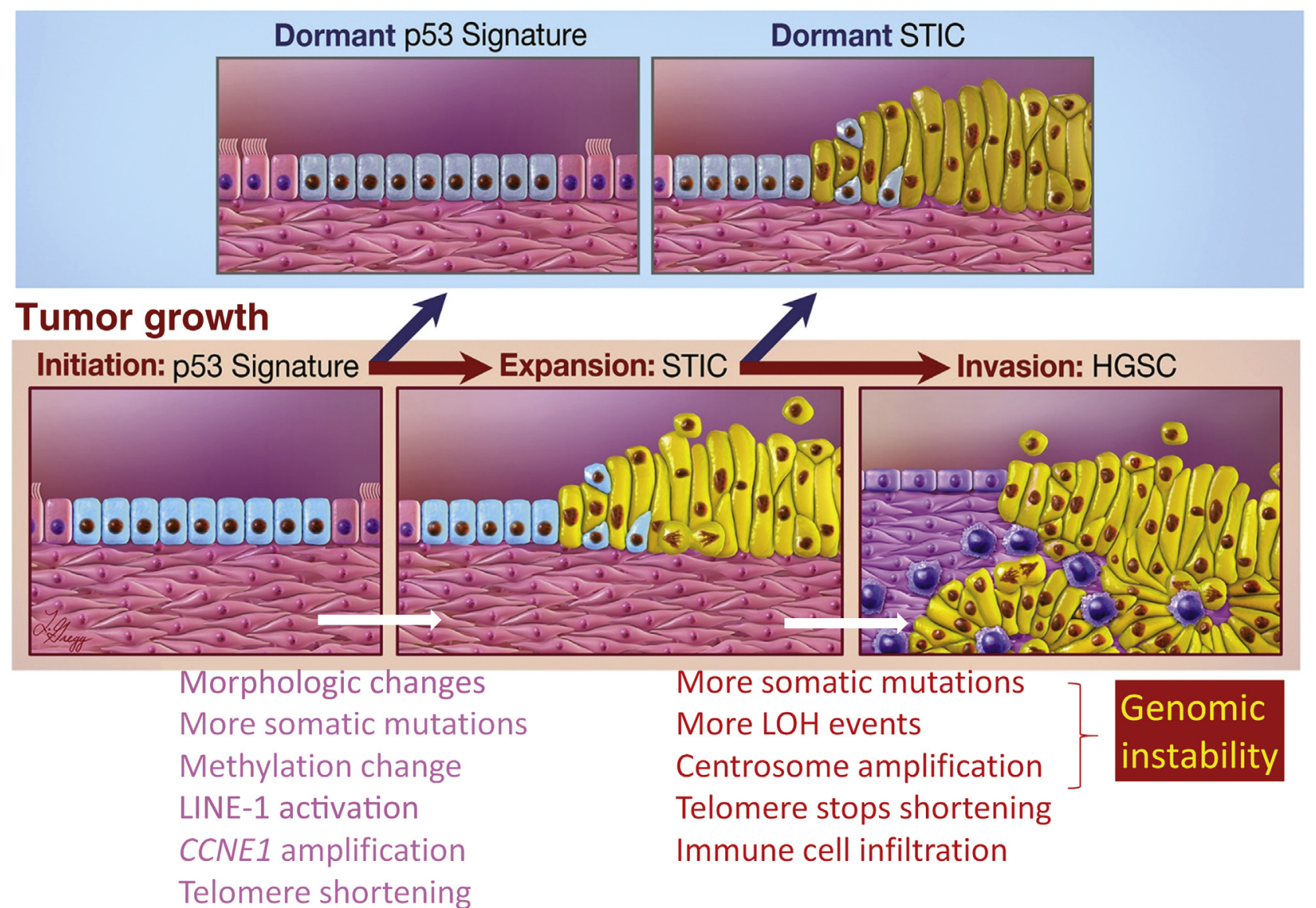

Figure 4 Molecular alterations associated with tumor progression from p53 signature to serous tubal intraepithelial carcinoma (STIC) to high-grade serous carcinoma (HGSC). After initial clonal expansion, p53 signatures and some STICs become dormant as they lose a proliferative advantage. But some STICs continue to proliferate, gain additional cancer-promoting events, and progress to HGSC spreading to fallopian tubes, ovaries, and other pelvic organs. Compared to $\mathrm{p} 53$ signatures, STICs gain several features as listed, and may be involved in the progression. Similarly, as compared to STICs, HGSCs are more frequently characterized by features related to genomic instability, maintenance of telomere length, and immune cell infiltration. LINE, long-interspersed element; LOH, loss of heterozygosity.

normal tissues, including bone marrow, colonic crypts, breast, and endometrial glands. ${ }^{40-43}$

By counting one-dimensional p53 stain-positive epithelial cells from p53 signatures on tissue sections, we estimated the mean total number of positive cells in a twodimensional p53 signature on the surface of fallopian tubes. Based on this number and the $\log _{2} r^{2} \pi$ formula, where $r$ is half of the number of p53 cells, we deduced that, on average, an individual progenitor cell undergoes approximately 10 to 12 doubling events to produce the progenies carrying the same TP53 mutation in a given p53 signature before the $\mathrm{p} 53$ signature undergoes proliferative quiescence. It has been established that at in each cell division, the daughter cells acquire a few mutations at random sites across the genome. ${ }^{43}$ In an uncommon event when the somatic mutations hit an oncogene or a tumor suppressor gene, these additional molecular events may increase the fitness of the cells to better survive and proliferate to become a STIC. However, from a molecular genetic perspective, this very low mutation rate may not sufficiently drive tumorigenesis, and could explain the relatively low incidence of HGSC in the general population. Whether the TP53 mutation itself can accelerate the mutation rate, reprogram the epigenome, and facilitate cancer-promoting mechanisms (eg, CCNE1 amplification or homologous recombination DNA repair deficiency) is uncertain. The tumor-suppressive effect of progesterone in ovarian and endometrial cancer is well known. The findings from a recent report suggest a possible mechanism, since in both mice (Trp53 ${ }^{--}$model) and humans, progesterone supplementation could eliminate p53-defective tubal epithelium by necroptosis through activating the tumor necrosis factor (TNF)- $\alpha$ /receptor-interacting serine/threonine-protein kinase (RIPK)-1/RIPK3/mixed-lineage kinase domain-like protein (MLKL) pathway. This suggests that before HGSC develops, progesterone may serve as a mechanism to prevent early tumorigenesis by eliminating progesterone receptor-positive p53 signatures. ${ }^{44}$

In addition to an increase in molecular genetic alterations, including somatic mutations and loss of heterozygosity, ${ }^{17}$ tumor initiation and progression have also been associated with aberrant expression of several cancer-related genes 
(Figure 4). The up-regulated genes known so far in STICs include STMN1, ${ }^{45,46} \mathrm{LAMCl},{ }^{47} \mathrm{RSF} 1, \mathrm{CCNE} 1$, and $\mathrm{FSN},{ }^{48}$ which are not up-regulated in the normal fallopian tube epithelium. Among down-regulated genes, $P A X 2$ is the most important. Loss of PAX2 protein has been shown in tubal precursors as early as the secretory cell overgrowth stage and in almost all STICs. ${ }^{32,49,50}$ PAX2, a member of the pair box gene family, is expressed in adult Müllerian derivatives, and is essential for urogenital morphogenesis. Loss of PAX2 expression has been associated with stem cell expansion during Müllerian development and maintenance of homeostasis in adult fallopian tube and, therefore, may be involved in tumorigenesis of HGSC. ${ }^{51,52}$

Telomere length reflects the cell division history, as telomeres gradually shorten each time a nontransformed cell divides. Thus, telomere length can serve as a molecular clock in some contexts. Telomere shortening has been observed in cancer precursors of prostate, lung, pancreatic, colon, breast, cervical, and biliary tract carcinomas. ${ }^{53-56}$ Thus, analysis of telomere lengths across p53 signatures, STIC, and HGSC yields new insight into pathogenesis. Most p53 signatures and incidental STICs without HGSC have been reported to manifest significant telomere shortening compared with their matched adjacent normalappearing fallopian tube epithelium. ${ }^{27}$ STICs associated with HGSC have been reported to exhibit the shortest telomeres among p53 signatures, incidental STICs without HGSC, and HGSC. ${ }^{27}$ Ultrashort telomeres in some STICs may contribute to chromosomal instability, as reflected in centrosome amplification and DNA copy number alterations (Figure 3), which trigger apoptosis or senescence. Thus, like mitotic figures, apoptotic bodies are frequently detected in a STIC, and serve as a reliable diagnostic feature of STIC. On the other hand, some of the STICs can activate telomerase reverse transcriptase to maintain telomere length, rescuing the cells from telomere-induced apoptosis/senescence and resulting in the acquisition of additional cancer-promoting mechanisms to progress to HGSC. ${ }^{57}$

Based on the number of somatic mutations and the lesionspecific proliferation rate, a multisegment tumor evolutionary timeline was calculated. The majority of HGSC precursors were estimated to appear in women as early as the late teens or early 20 s. It may take 2 decades or more for a p53 signature lesion to progress to an HGSC. This prolonged latency before the development of an invasive and disseminated carcinoma provides a relatively reasonable time window for prevention and surgical intervention. For example, oral contraceptive use has been associated with an approximately $50 \%$ reduction in ovarian cancer risk, ${ }^{58}$ and lipid-lowering statins have been reported to reduce the formation of STIC in a preclinical mouse model. ${ }^{59}$

However, it may take as few as 6 years for a STIC to progress to an HGSC, indicating accelerated tumor progression during this stage, and a much narrower window for early detection and intervention. ${ }^{17}$ This proposed timeline is remarkably similar to the estimate from a study that assessed the time effects of oral contraceptive use or pregnancy in the prevention of ovarian cancer alongside other clinicopathologic parameters. ${ }^{60}$ In that study, the natural history began at first ovulation in an adolescent, requiring 10 years from first ovulation for normal tubal epithelium to acquire the p53 signature, another 15 years to STIC, and over 5 years to progress to HGSC. ${ }^{60}$

\section{Epigenetic Alterations in Developing STIC}

Despite its aggressive nature, HGSC, unlike type 1 ovarian carcinomas, surprisingly does not contain prominent recurrent mutations other than TP53. This is also true for STIC and p53 signature, as genome-wide analyses fail to identify consistent and reproducible molecular genetic alterations. It has become increasingly clear that TP53 mutation alone is insufficient for propelling tumor progression, given that p53 signatures are histologically indistinguishable from adjacent TP53 wild-type tubal epithelium, and the p53-signature epithelial cells have a low (background) level of proliferative activity. The above finding raises the possibility that epigenetic changes collaborate with other molecular changes (TP53 mutation, amplification/deletion of cancer driver genes, alterations in miRNAs, etc) to drive neoplastic transformation, especially in association with genetic predisposition such as $B R C A 1$ and $B R C A 2$ germline mutations. The stochastic nature of epigenetic alterations, like molecular genetic changes, can increase the heterogeneity of cells for selection, a main driving force in tumor evolution.

Two recent studies employed the MethylationEPIC platform to globally profile methylation alterations in various gynecologic malignancies, including HGSCs, STICs, p53 signature, and adjacent normal-appearing fallopian tube epithelium. $^{28,29}$ The first report discovered a total of 91 regions of robust, HGSC-specific hypermethylation, and the top performance of these markers was found to also be hypermethylated in STICs. More interestingly, hypermethylation of some of the genes was detected in adjacent normal-appearing fallopian tubal epithelium but not in fallopian tube epithelium from distally located regions, or from healthy women without HGSC or STIC. In the second study, genome-wide methylation analysis was directly performed on STIC and p53 signature lesions. Unsupervised analysis of the 1000 most differentially methylated $\mathrm{CpG}$ probes showed that STICs largely clustered with HGSCs, but were clearly distinct from adjacent normal fallopian tube epithelium. Notably, the p53 signature clustered with adjacent normal epithelium, indicating that the p53 signature carried a largely normal methylome. Importantly, this study identified 42 genomic regions that exhibited highconfidence STIC-specific differential hypermethylation, of which 17 (40.5\%) directly overlapped with HGSC-specific differentially methylated regions. These observations suggest that aberrant methylation is likely an early event in HGSC carcinogenesis. 
In addition to promoter and enhancer hypermethylation, which is associated with down-regulation of gene expression, hypomethylation can play a role in up-regulating certain genes. Ten-eleven translocation methylcytosine dioxygenase (TET)-1 is an enzyme involved in active DNA demethylation. TET1 was recently shown to be up-regulated in STICs and HGSCs compared to normal-appearing fallopian tube epithelium, ${ }^{61}$ suggesting that epigenetic reprogramming contributes to HGSC development through upregulating genes involved in tumor-promoting pathways. The presumptive cancer-promoting gene CSNK2Al, which encodes casein kinase II subunit $\alpha(\mathrm{CK} 2 \alpha)$, and longinterspersed element (LINE)-1, are two examples of genes subject to promoter/enhancer hypomethylation in STICs. ${ }^{61,62}$

\section{Other Origins of HGSC Independent of STIC}

Are all HGSCs derived from STICs? Or more importantly, what percentage of HGSCs develop from a pre-existing STIC? It is difficult to answer either question with confidence unless the true prevalence of a tubal lesion is known. A close estimation is that approximately half of the fallopian tubes accompanied by HGSCs contain STICs; however, that leaves a significant number of HGSCs for which precursors cannot be identified. ${ }^{8,20,21}$ The above finding can be explained by the fact that routine tissue sampling and tissue sectioning are likely to miss a STIC or a p53 signature. Even when an entire fallopian tube is submitted for tissue processing, only a small fraction can be examined microscopically, given that the bulk of tissue remains in paraffin, and thus is not available for examination. This underdiagnosis argument is supported by reports showing an increase in the number of tubal lesions identified when the paraffin tissue is extensively sampled and carefully examined, by methods such as inverting a tissue block and resectioning. ${ }^{20}$ Nonetheless, it is reasonable to postulate that not all HGSCs develop via a STIC-to-HGSC sequence. ${ }^{63}$

What then, are the alternative origins? A host of other mechanisms have come to light. Clinicopathologic and molecular studies together with anecdotal evidence have shown that HGSCs can be associated with ovarian serous borderline tumor, ovarian low-grade serous carcinoma, ovarian serous cystadenoma, ovarian cortical inclusion cyst, and ovarian surface adenofibroma. ${ }^{1,64}$ There is currently no evidence that shows dysplasia involving ovarian surface mesothelial cells in a way similar to a STIC, or an incipient HGSC directly arising from these cells. It would not be surprising if future case reports demonstrate an early HGSC genesis on the ovarian surface where the overlying mesothelial cells are replaced by tubal mucosa due to severe tubal-ovarian adhesion. Evidence is lacking on whether HGSC can develop from the vestigial remnants of Müllerian epithelium located at the soft tissues near ovary and fallopian tube.
A morphologic and molecular genetic analysis provides cogent evidence that, although uncommon, HGSC can develop from concurrent serous borderline tumors and lowgrade serous carcinomas. ${ }^{64-66}$ Metachronous analysis of ovarian serous borderline tumors in some cases also demonstrates the development of subsequent HGSC. ${ }^{67}$ Several of these HGSCs harbor KRAS but not TP53 mutations, an unusual finding in HGSCs developing from the conventional pathway. Other origins are rare, resulting in unusual cases (Figure 5). Thus, the genesis of HGSC may follow alternative pathways independent of the STIC-HGSC sequence. Interestingly, ovarian low-grade serous carcinoma and its precursor lesion, serous borderline tumor, as well as endosalpingiosis and the tubal-type ovarian cortical inclusion cysts are all derivatives of fallopian tube epithelium. Thus, HGSCs arising from these lesions can, in theory, be traced back to fallopian tube epithelial cells. ${ }^{9}$ Thus, two main pathways of HGSC development have been proposed. One is the canonical STIC pathway, in which malignant transformation occurs directly on the fallopian tube. The other is an alternative pathway in which transformation to HGSC takes place ectopically in fallopian tube-related lesions in the ovary. The presence of HGSCs not related to STICs does not refute, but expands the tubal paradigm, given that HGSCs from both pathways are descendants of fallopian tube epithelium. Thus, it is unsurprising that the RNA transcriptome and the miRNA data do not reveal clear separation between HGSCs with and without STIC lesions. $^{22}$

\section{Clinical Implications of the Tubal Paradigm}

\section{Prophylactic and Opportunistic Salpingectomy}

In women with a genetic predisposition to ovarian cancer, prophylactic bilateral salpingo-oophorectomy has significantly decreased the risk for ovarian cancer, and has become the standard of care. However, removal of the ovaries prematurely has been associated with significant pathologic sequelae, as reported by the Nurses' Health Study of 30,000 women. Investigators in that study did not identify an overall survival benefit from bilateral oophorectomy at any age because of the low incidence of ovarian cancer. Rather, there was a substantial increase in mortality in those women due to coronary heart disease, cancer (lung and colorectal), and other causes. ${ }^{68}$ The paradigm shift from ovarian to tubal origin of HGSC should lead to the adoption of a more rational approach to treating high-risk women, specifically, bilateral prophylactic salpingectomy with ovarian conservation, which can preserve both fertility and hormone function. Oophorectomy can then be postponed until the woman approaches menopause. The precise time when salpingectomy should be performed has been a subject of debate. Given that STICs are rarely associated with invasive carcinoma or disseminated disease in women under the age of $50,{ }^{69,70}$ it is proposed that prophylactic salpingectomy 
A
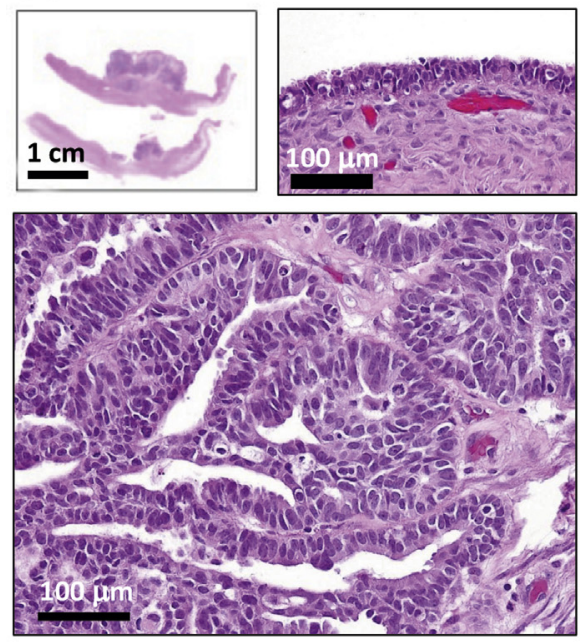

B
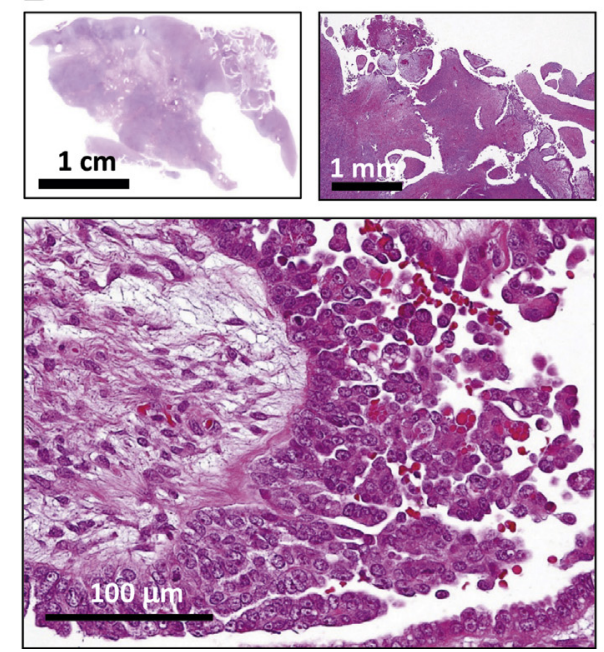

C
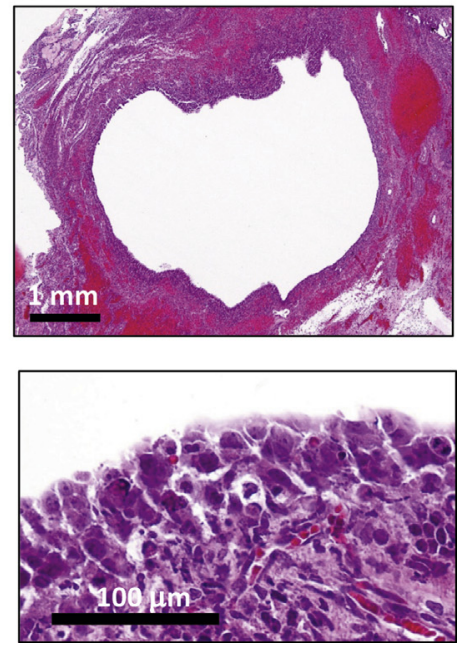

Figure 5 Alternative pathways in the development of high-grade serous carcinoma (HGSC). A: HGSC arising from an ovarian serous cystadenoma. Top left panel: A low-magnification view showing the wall of the cystadenoma with a focal solid growth of HGSC. Top right panel: Normal-appearing epithelium surrounding the solid tumor. Bottom panel: Histologic features of an HGSC. B: HGSC developing directly on the ovarian surface. Top left panel: A lowmagnification view showing the whole ovarian section. Top right panel: The ovarian surface showing adenofibroma where the HGSC arises. Bottom panel: HGSC on the surface of adenofibroma. C: HGSC arising from an enlarged ovarian cortical inclusion cyst. Top panel: A low-magnification view of the inclusion cyst. Bottom panel: Highly atypical cells appearing on the surface of the cyst. Scale bars: $100 \mu \mathrm{m}$ (A, top right panel and bottom panel; B, bottom panel; C, bottom panel); $1 \mathrm{~mm}$ (B, top right panel; $C$, top panel); $1 \mathrm{~cm}$ (A, top left panel; B, top left panel).

can be reasonably considered in high-risk women until 45 years of age.

Similarly, in average-risk women undergoing hysterectomy for benign diseases, bilateral salpingectomy without the removal of the ovaries is now advocated. ${ }^{71}$ This opportunistic salpingectomy may, in theory, reduce the risk for HGSC, at least from a population perspective; however, because the incidence of HGSC in the general population is low, the significance is questionable. Nonetheless, salpingectomy, rather than simple tubal ligation, is often recommended for permanent contraception.

\section{Early Detection of HGSC Using Liquid-Based Papanicolaou Samples}

Early detection of cancer is believed to significantly decrease cancer-associated morbidity and mortality by enabling surgical removal of early-stage and organ-confined tumors, performed either as an intent to cure, or to increase the likelihood of successful treatment in women with low tumor burden. Cancer-screening paradigms, such as Papanicolaou smear cytology, stool DNA test, and mammograms, have successfully shifted the diagnosis from symptom-detected to screening-detected cancer. This practice has been known to reduce cancer-associated mortality and morbidity. However, this success has not been reproduced in ovarian cancer, which is anatomically located deep in the pelvic cavity. Several large-scale screening trials incorporating protein biomarkers such as CA-125, and/or imaging modalities such as transvaginal ultrasound, have yet to demonstrate a meaningful survival benefit. ${ }^{72,73}$ Thus, early diagnosis of ovarian cancer represents a seemingly insuperable hurdle in light of potential harm outweighing potential benefit.

The predicament in the early diangosis of ovarian cancer, however, seems to be challenged. The tubal paradigm - that most ovarian HGSCs arise from fallopian tubes that are directly communicable with endometrial cavity and cervix - has brought a renewed hope for the early detection of HGSC in asymptomatic women, even at its precursor stage. This detection is possible because the cancer cells derived from STICs or incipient HGSC can travel from fallopian tubes down to the cervix, where they can be collected for analysis. ${ }^{74}$ Indeed, a prototypic assay, PapGene, has been developed using routine liquid-based Papanicolaou specimens, which allows the detection of rare copy mutations in a small set of selected genes, including TP53, against a background of an overwhelming amount of normal DNA. ${ }^{75}$ In a follow-up study to increase the sensitivity of PapGene, the PapSEEK, which incorporates assays of mutations in 18 genes and an assay for aneuploidy, was developed. ${ }^{75,76}$ The sensitivity of PapSEEK was $33 \%$, including $34 \%$ of patients with earlystage disease, and the specificity was nearly $99 \%$. With the analysis of plasma DNA, the combined tests increased the sensitivity for ovarian cancer detection to $63 \%$. These results clearly demonstrate the potential of DNA-based diagnostics to detect ovarian cancers at a stage at which they are more likely to be curable by surgery and/or chemotherapy.

Despite this promise, the persistent challenge, now as in the past, is the lack of cancer type-specific biomarkers that can distinguish ovarian carcinomas from other gynecologic malignancies and from benign lesions such as adenomyosis 
and endometrial polyp. Further complicating the specificity is that normal endometrial glands harbor somatic mutations, including cancer driver mutations. ${ }^{41}$ This finding is theoretically expected to increase false-positive cases. One of the solutions would be to undertake clinical studies to determine methylation markers. Methylation patterns have been shown to better differentiate tissue types and to identify the cancer of origin (eg, ovarian versus endometrial carcinoma), ${ }^{77-79}$ and, as compared to gene mutations, over-representation of hypermethylated loci can be developed to improve overall clinical sensitivity and specificity. ${ }^{28,80,81}$ Other biomarkers including cancer antigen (CA)-125 and human epididymis (HE)-4 can also be included in developing a multimarker test for increasing sensitivity without sacrificing high specificity. Ultimately, a sufficiently large prospective interventional trial will be required for testing this approach in the target high-risk population (BRCA carriers or patients with a family history of breast/ovarian cancer). When introduced in clinics, the test-positive women will be further evaluated using imaging modalities (eg, transvaginal sonography) before surgical intervention can be considered.

\section{Challenges and Future Directions}

\section{Clinical Significance of Incidental STIC}

Unlike a precursor lesion or an in situ carcinoma from other types of epithelial cancer for which surgical removal always lead to cure, STIC may, theoretically, disseminate before salpingectomy. ${ }^{82}$ This phenomenon may explain why some women with inherited mutations in BRCA1/2 develop peritoneal HGSC even after their fallopian tubes and ovaries have been prophylactically removed. ${ }^{83,84} \mathrm{~A}$ clinicopathologic correlation study has suggested that non-high-risk women who are diagnosed with incidental STICs should receive a complete staging surgery and be offered hereditary testing. ${ }^{85}$ Larger-scale clinical studies are needed for determining the risk of an incidental STIC subsequently developing into an HGSC. Moreover, not all STICs are generated equal, and it is possible that some STICs present a higher risk than others. There is some controversy regarding the appropriate management of women with a STIC in the absence of tumor elsewhere. Preliminary studies in rare cases have shown recurrences, ${ }^{86,87}$ suggesting that perhaps not all STICs progress to HGSCs. Some investigators have argued that women diagnosed with STIC after prophylactic salpingooophorectomy may not need adjuvant chemotherapy. ${ }^{86}$ Thus, a risk-prediction model that incorporates molecular data will be crucial for guiding clinical management in women with incidental STICs.

\section{Standard Diagnosis of STIC}

The availability of a correct and reproducible diagnosis of precancerous lesions, including STIC, is of utmost importance for studies addressing the early pathogenesis, early detection, chemoprevention, and clinical management of HGSC. However, there are two main challenges. First, consistency of diagnosis remains poor among pathologists, although diagnostic criteria for STIC have been proposed. ${ }^{88}$ Second, because of its minute size, a STIC can be inadvertently missed in routine pathology examination. Morphology-based, on-line training may be of benefit to practicing pathologists who wish to become more familiar with the diagnosis of STICs. A futuristic but pragmatic approach to developing a computer-assisted intelligence platform for screening hematoxylin and eosin-stained fallopian tube sections for potential STIC lesions would be helpful, especially for screening women at high risk. Pathologists can send images to a centralized server that runs image-based analysis, which can annotate those regions that require pathologists' attention and validation. Once regions suspicious for STIC are selected using morphology-based screening, tissue biomarkers can then be applied to confirm the diagnosis. Although intense and diffuse p53 staining provides a useful marker of STICs, this abnormal staining pattern is absent in approximately one-third of STICs because of TP53 inactivation of mutations, resulting in loss of p53 protein. An immunostaining marker that can universally detect STICs, regardless of TP53 mutation type, would be useful. Future studies should compare the sensitivity and specificity of published STIC markers, including PAX2, stathmin, laminin $\gamma 1$, p16, high-mobility group protein (HMGA)-2, and cyclin E1, ${ }^{45-47}$ to determine whether a single specific marker is sufficient or whether a combination of markers would further improve performance.

\section{Pathogenesis of STIC Outside of TP53 Mutation}

Other than TP53 mutations and CCNE1 copy number gains, STICs exhibit few recurrent molecular genetic aberrations. Therefore, the identification of changes in epigenetics, epigenomics, miRNAs, microbiome, and proteomics (especially post-translational modifications), may offer important insights into the early pathogenesis of HGSC. However, there are challenges ahead. Technologies suitable for the analysis of the scant and often degraded biomolecules from minute laser-capture microdissected paraffin-embedded lesions are yet to be improved. Single-cell technologies with a capacity to analyze a few lesion cells in paraffin tissues will help understand the precancerous landscape of precursor lesions. Multiplex immunostaining and in situ hybridization may offer a convenient approach before micro-omics analysis becomes a reality. Another challenge is the confounding factor that some of the STICs in association with HGSC may represent seeding back of peritoneal HGSC cells, mimicking de novo STICs. Thus, the proximal positioning of an HGSC and a STIC does not guarantee the rise of HGSC directly from the adjacent STIC. Further complicating the delineation of the clonal relationship between 
STIC, p53 signature, and HGSC from the same patient is the intratumoral heterogeneity, especially in HGSC. Different interpretations of data may depend on which part of the HGSC is studied and compared to the matched STIC or p53 signatures. To overcome these challenges and to provide for a meaningful comparison, future molecular studies should carefully select for analysis STIC/HGSC pairs in which the HGSC is small and is at an early stage. Likewise, molecular analyses should include incidental STICs in the absence of synchronous HGSC. These unusual STICs represent the most clean precursor lesions for studying molecular pathogenesis before cancer arises. Finally, STICs can be associated with uterine serous carcinomas, either as a precursor or as a metastasis, ${ }^{89,90}$ and other metastatic carcinomas can spread to fallopian tube mucosa and masquerade as STIC lesions. ${ }^{91,92}$ Future study design should consider this factor to rule out possible STIC mimickers.

\section{Conclusion}

The emerging tubal paradigm is expected to affect ovarian cancer research and gynecology practice. Recent studies, especially those that analyzed the incidental STICs and p53 signatures without HGSC, have contributed to a better understanding of the molecular etiology in the tumor initiation of HGSC. The research is starting to suggest the presence of multiple and molecularly heterogeneous STICs at a precancerous stage, and telomere shortening observed in STICs serves a rate-limiting selection pressure for some STICs that escape this bottleneck and eventually progress to HGSC. The extant STIC associated with HGSC at diagnosis may represent a close cousin of the original precursor, which is minute, and has been effaced by the aggressive carcinoma. From a clinical perspective, two major implications stand out: one is the recommendation of performing prophylactic and opportunistic salpingectomy without oophorectomy, thus intercepting tumor progression while preserving ovarian hormone function. The other is the early detection of HGSC and STIC in routine cervical liquid-based Papanicolaou specimens. If future studies can demonstrate an improved clinical outcome with the adoption of these approaches, patients and physicians would be well-positioned to witness a monumental bonus from this paradigm shift.

\section{References}

1. Kurman RJ, Shih IM: The origin and pathogenesis of epithelial ovarian cancer: a proposed unifying theory. Am J Surg Pathol 2010, $34: 433-443$

2. Kurman RJ, Shih IeM: The Dualistic model of ovarian carcinogenesis: revisited, revised, and expanded. Am J Pathol 2016, 186 : 733-747

3. Shih IeM, Panuganti PK, Kuo KT, Mao TL, Kuhn E, Jones S, Velculescu VE, Kurman RJ, Wang TL: Somatic mutations of PPP2R1A in ovarian and uterine carcinomas. Am J Pathol 2011, 178: $1442-1447$
4. Maeda D, Shih IeM: Pathogenesis and the role of ARID1A mutation in endometriosis-related ovarian neoplasms. Adv Anat Pathol 2013, 20:45-52

5. Kuhn TS, Hacking I: The Structure of Scientific Revolutions. ed 4 Chicago, The University of Chicago Press, 2012

6. Piek JM, van Diest PJ, Zweemer RP, Jansen JW, Poort-Keesom RJ, Menko FH, Gille JJ, Jongsma AP, Pals G, Kenemans P, Verheijen RH: Dysplastic changes in prophylactically removed fallopian tubes of women predisposed to developing ovarian cancer. J Pathol 2001, 195:451-456

7. Piek JM, Verheijen RH, Kenemans P, Massuger LF, Bulten H, van Diest PJ: BRCA1/2-related ovarian cancers are of tubal origin: a hypothesis. Gynecol Oncol 2003, 90:491

8. Kindelberger DW, Lee Y, Miron A, Hirsch MS, Feltmate C, Medeiros F, Callahan MJ, Garner EO, Gordon RW, Birch C, Berkowitz RS, Muto MG, Crum CP: Intraepithelial carcinoma of the fimbria and pelvic serous carcinoma: evidence for a causal relationship. Am J Surg Pathol 2007, 31:161-169

9. Vang R, Shih IeM, Kurman RJ: Fallopian tube precursors of ovarian low- and high-grade serous neoplasms. Histopathology 2013, 62: $44-58$

10. Vang R, Visvanathan K, Gross A, Maambo E, Gupta M, Kuhn E, Li RF, Ronnett BM, Seidman JD, Yemelyanova A, Shih IeM, Shaw PA, Soslow RA, Kurman RJ: Validation of an algorithm for the diagnosis of serous tubal intraepithelial carcinoma. Int $\mathrm{J}$ Gynecol Pathol 2012, 31:243-253

11. Crum CP, McKeon FD, Xian W: BRCA, the oviduct, and the space and time continuum of pelvic serous carcinogenesis. Int J Gynecol Cancer 2012, 22 Suppl 1:S29-S34

12. Kuhn E, Kurman RJ, Sehdev AS, Shih IeM: Ki-67 labeling index as an adjunct in the diagnosis of serous tubal intraepithelial carcinoma. Int J Gynecol Pathol 2012, 31:416-422

13. Soong TR, Kolin DL, Teschan NJ, Crum CP: Back to the future? The fallopian tube, precursor escape and a dualistic model of high-grade serous carcinogenesis. Cancers (Basel) 2018, $10: 468$

14. Crum CP, Drapkin R, Miron A, Ince TA, Muto M, Kindelberger DW Lee Y: The distal fallopian tube: a new model for pelvic serous carcinogenesis. Curr Opin Obstet Gynecol 2007, 19:3-9

15. Lee Y, Miron A, Drapkin R, Nucci MR, Medeiros F, Saleemuddin A, Garber J, Birch C, Mou H, Gordon RW, Cramer DW, McKeon FD, Crum CP: A candidate precursor to serous carcinoma that originates in the distal fallopian tube. J Pathol 2007, 211:26-35

16. Folkins AK, Jarboe EA, Saleemuddin A, Lee Y, Callahan MJ, Drapkin R, Garber JE, Muto MG, Tworoger S, Crum CP: A candidate precursor to pelvic serous cancer ( 553 signature) and its prevalence in ovaries and fallopian tubes from women with BRCA mutations. Gynecol Oncol 2008, 109:168-173

17. Wu RC, Wang P, Lin SF, Zhang M, Song Q, Chu T, Wang BG, Kurman RJ, Vang R, Kinzler K, Tomasetti C, Jiao Y, Shih IM, Wang TL: Genomic landscape and evolutionary trajectories of ovarian cancer precursor lesions. J Pathol 2019, 248:41-50

18. Labidi-Galy SI, Papp E, Hallberg D, Niknafs N, Adleff V, Noe M, Bhattacharya R, Novak M, Jones S, Phallen J, Hruban CA, Hirsch MS, Lin DI, Schwartz L, Maire CL, Tille JC, Bowden M, Ayhan A, Wood LD, Scharpf RB, Kurman R, Wang TL, Shih IM, Karchin R, Drapkin R, Velculescu VE: High grade serous ovarian carcinomas originate in the fallopian tube. Nat Commun 2017, 8: 1093

19. Eckert MA, Pan S, Hernandez KM, Loth RM, Andrade J, Volchenboum SL, Faber P, Montag A, Lastra R, Peter ME, Yamada SD, Lengyel E: Genomics of ovarian cancer progression reveals diverse metastatic trajectories including intraepithelial metastasis to the fallopian tube. Cancer Discov 2016, 6:1342-1351

20. Visvanathan K, Shaw P, May BJ, Bahadirli-Talbott A, Kaushiva A, Risch H, Narod S, Wang TL, Parkash V, Vang R, Levine DA, Soslow R, Kurman R, Shih IM: Fallopian tube lesions in women at 
high risk for ovarian cancer: a multicenter study. Cancer Prevent Res 2018, 11:697-706

21. Przybycin CG, Kurman RJ, Ronnett BM, Shih IM, Vang R: Are all pelvic (nonuterine) serous carcinomas of tubal origin? Am J Surg Pathol 2010, 34:1407-1416

22. Ducie J, Dao F, Considine M, Olvera N, Shaw PA, Kurman RJ, Shih IM, Soslow RA, Cope L, Levine DA: Molecular analysis of high-grade serous ovarian carcinoma with and without associated serous tubal intra-epithelial carcinoma. Nat Commun 2017, 8:990

23. Beirne JP, McArt DG, Roddy A, McDermott C, Ferris J, Buckley NE, Coulter P, McCabe N, Eddie SL, Dunne PD, O'Reilly P, Gilmore A, Feeney L, Ewing DL, Drapkin RI, Salto-Tellez M, Kennedy RD, Harley IJG, McCluggage WG, Mullan PB: Defining the molecular evolution of extrauterine high grade serous carcinoma. Gynecol Oncol 2019, 155:305-317

24. Hu Z, Artibani M, Alsaadi A, Wietek N, Morotti M, Shi T, Zhong Z, Santana Gonzalez L, El-Sahhar S, KaramiNejadRanjbar M, Mallett G, Feng Y, Masuda K, Zheng Y, Chong K, Damato S, Dhar S, Campo L, Garruto Campanile R, Soleymani Majd H, Rai V, Maldonado-Perez D, Jones S, Cerundolo V, Sauka-Spengler T, Yau C, Ahmed AA: The repertoire of serous ovarian cancer nongenetic heterogeneity revealed by single-cell sequencing of normal fallopian tube epithelial cells. Cancer Cell 2020, 37:226-242.e7

25. Kuhn E, Kurman RJ, Vang R, Sehdev AS, Han G, Soslow R, Wang TL, Shih IM: TP53 mutations in serous tubal intraepithelial carcinoma and concurrent pelvic high-grade serous carcinoma- evidence supporting the clonal relationship of the two lesions. J Pathol 2012, 226:421-426

26. Kuhn E, Meeker A, Wang TL, Sehdev AS, Kurman RJ, Shih IeM: Shortened telomeres in serous tubal intraepithelial carcinoma: an early event in ovarian high-grade serous carcinogenesis. Am J Surg Pathol 2010, 34:829-836

27. Asaka S, Davis C, Lin SF, Wang TL, Heaphy CM, Shih IM: Analysis of telomere lengths in p53 signatures and incidental serous tubal intraepithelial carcinomas without concurrent ovarian cancer. Am J Surg Pathol 2019, 43:1083-1091

28. Pisanic TR 2nd, Cope LM, Lin SF, Yen TT, Athamanolap P, Asaka R, Nakayama K, Fader AN, Wang TH, Shih IM, Wang TL: Methylomic analysis of ovarian cancers identifies tumor-specific alterations readily detectable in early precursor lesions. Clin Cancer Res 2018, 24:6536-6547

29. Pisanic TR 2nd, Wang Y, Li L, Cope L, Considene M, Sun H, Wang TZ, Wang TL, Shih IM: The methylomic landscape of fallopian tube lesions associated with ovarian high-grade serous carcinoma. Clin Cancer Res 2020. [Epub ahead of print] doi:10.1158/ 1078-0432.CCR-20-0270

30. Perets R, Wyant GA, Muto KW, Bijron JG, Poole BB, Chin KT, Chen JY, Ohman AW, Stepule CD, Kwak S, Karst AM, Hirsch MS, Setlur SR, Crum CP, Dinulescu DM, Drapkin R: Transformation of the fallopian tube secretory epithelium leads to high-grade serous ovarian cancer in Brca;Tp53;Pten models. Cancer Cell 2013, 24: $751-765$

31. Sherman-Baust CA, Kuhn E, Valle BL, Shih IeM, Kurman RJ, Wang TL, Amano T, Ko MS, Miyoshi I, Araki Y, Lehrmann E, Zhang Y, Becker KG, Morin PJ: A genetically engineered ovarian cancer mouse model based on fallopian tube transformation mimics human high-grade serous carcinoma development. J Pathol 2014, 233:228-237

32. Chen EY, Mehra K, Mehrad M, Ning G, Miron A, Mutter GL, Monte N, Quade BJ, McKeon FD, Yassin Y, Xian W, Crum CP: Secretory cell outgrowth, PAX2 and serous carcinogenesis in the Fallopian tube. J Pathol 2010, 222:110-116

33. Wang Y, Li L, Wang Y, Tang SN, Zheng W: Fallopian tube secretory cell expansion: a sensitive biomarker for ovarian serous carcinogenesis. Am J Transl Res 2015, 7:2082-2090

34. Li L, Yue P, Song Q, Yen TT, Asaka S, Wang TL, Beavis AL, Fader AN, Jiao Y, Yuan G, Shih IM, Song Y: Genome-wide mutation analysis in precancerous lesions of endometrial carcinoma. The
Journal of Pathology 2020, [Epub ahead of print] doi:10.1002/path. 5566

35. Bashashati A, Ha G, Tone A, Ding J, Prentice LM, Roth A, Rosner J, Shumansky K, Kalloger S, Senz J, Yang W, McConechy M, Melnyk N, Anglesio M, Luk MT, Tse K, Zeng T, Moore R, Zhao Y, Marra MA, Gilks B, Yip S, Huntsman DG, McAlpine JN, Shah SP: Distinct evolutionary trajectories of primary high-grade serous ovarian cancers revealed through spatial mutational profiling. J Pathol 2013, 231:21-34

36. Fathalla MF: Incessant ovulation and ovarian cancer-a hypothesis revisited. Facts Views Vis Obgyn 2013, 5:292-297

37. Huang HS, Chu SC, Hsu CF, Chen PC, Ding DC, Chang MY, Chu TY: Mutagenic, surviving and tumorigenic effects of follicular fluid in the context of p53 loss: initiation of fimbria carcinogenesis. Carcinogenesis 2015, 36:1419-1428

38. Hsu CF, Huang HS, Chen PC, Ding DC, Chu TY: IGF-axis confers transformation and regeneration of fallopian tube fimbria epithelium upon ovulation. EBioMedicine 2019, 41:597-609

39. Vang R, Gupta M, Wu LS, Yemelyanova AV, Kurman RJ, Murphy KM, Descipio C, Ronnett BM: Diagnostic reproducibility of hydatidiform moles: ancillary techniques (p57 immunohistochemistry and molecular genotyping) improve morphologic diagnosis. Am J Surg Pathol 2012, 36:443-453

40. Jaiswal S, Fontanillas P, Flannick J, Manning A, Grauman PV, Mar BG, Lindsley RC, Mermel CH, Burtt N, Chavez A, Higgins JM, Moltchanov V, Kuo FC, Kluk MJ, Henderson B, Kinnunen L, Koistinen HA, Ladenvall C, Getz G, Correa A, Banahan BF, Gabriel S, Kathiresan S, Stringham HM, McCarthy MI, Boehnke M, Tuomilehto J, Haiman C, Groop L, Atzmon G, Wilson JG, Neuberg D, Altshuler D, Ebert BL: Age-related clonal hematopoiesis associated with adverse outcomes. N Engl J Med 2014, 371: $2488-2498$

41. Moore L, Leongamornlert D, Coorens THH, Sanders MA, Ellis P, Dentro SC, Dawson KJ, Butler T, Rahbari R, Mitchell TJ, Maura F, Nangalia J, Tarpey PS, Brunner SF, Lee-Six H, Hooks Y, Moody S, Mahbubani KT, Jimenez-Linan M, Brosens JJ, IacobuzioDonahue CA, Martincorena I, Saeb-Parsy K, Campbell PJ, Stratton MR: The mutational landscape of normal human endometrial epithelium. Nature 2020, 580:640-646

42. Wang X, Stolla M, Ring BZ, Yang Q, Laughlin TS, Rothberg PG, Skinner K, Hicks DG: p53 alteration in morphologically normal/benign breast tissue in patients with triple-negative high-grade breast carcinomas: breast p53 signature? Hum Pathol 2016, 55: 196-201

43. Tomasetti C, Vogelstein B: Cancer etiology. Variation in cancer risk among tissues can be explained by the number of stem cell divisions. Science 2015, 347:78-81

44. Wu NY, Huang HS, Chao TH, Chou HM, Fang C, Qin CZ, Lin CY, Chu TY, Zhou HH: Progesterone prevents high-grade serous ovarian cancer by inducing necroptosis of p53-defective fallopian tube epithelial cells. Cell Rep 2017, 18:2557-2565

45. Karst AM, Levanon K, Duraisamy S, Liu JF, Hirsch MS, Hecht JL, Drapkin R: Stathmin 1, a marker of PI3K pathway activation and regulator of microtubule dynamics, is expressed in early pelvic serous carcinomas. Gynecol Oncol 2011, 123:5-12

46. Novak M, Lester J, Karst AM, Parkash V, Hirsch MS, Crum CP, Karlan BY, Drapkin R: Stathmin 1 and p16(INK4A) are sensitive adjunct biomarkers for serous tubal intraepithelial carcinoma. Gynecol Oncol 2015, 139:104-111

47. Kuhn E, Kurman RJ, Soslow RA, Han G, Sehdev AS, Morin PJ, Wang TL, Shih IeM: The diagnostic and biological implications of laminin expression in serous tubal intraepithelial carcinoma. Am J Surg Pathol 2012, 36:1826-1834

48. Sehdev AS, Kurman RJ, Kuhn E, Shih IeM: Serous tubal intraepithelial carcinoma upregulates markers associated with high-grade serous carcinomas including Rsf-1 (HBXAP), cyclin E and fatty acid synthase. Mod Pathol 2010, 23:844-855 
49. Roh MH, Yassin Y, Miron A, Mehra KK, Mehrad M, Monte NM Mutter GL, Nucci MR, Ning G, McKeon FD, Hirsch MS, Wa X, Crum CP: High-grade fimbrial-ovarian carcinomas are unified by altered p53, PTEN and PAX2 expression. Mod Pathol 2010, 23: 1316-1324

50. Quick CM, Ning G, Bijron J, Laury A, Wei TS, Chen EY, Vargas SO, Betensky RA, McKeon FD, Xian W, Crum CP: PAX2null secretory cell outgrowths in the oviduct and their relationship to pelvic serous cancer. Mod Pathol 2012, 25:449-455

51. Ning G, Bijron JG, Yamamoto Y, Wang X, Howitt BE, Herfs M, Yang E, Hong $\mathrm{Y}$, Cornille $\mathrm{M}$, Wu L, Hanamornroongruang S, McKeon FD, Crum CP, Xian W: The PAX2-null immunophenotype defines multiple lineages with common expression signatures in benign and neoplastic oviductal epithelium. J Pathol 2014, 234: 478-487

52. Alwosaibai K, Abedini A, Al-Hujaily EM, Tang Y, Garson K, Collins O, Vanderhyden BC: PAX2 maintains the differentiation of mouse oviductal epithelium and inhibits the transition to a stem celllike state. Oncotarget 2017, 8:76881-76897

53. Meeker AK, Hicks JL, Iacobuzio-Donahue CA, Montgomery EA, Westra WH, Chan TY, Ronnett BM, De Marzo AM: Telomere length abnormalities occur early in the initiation of epithelial carcinogenesis. Clin Cancer Res 2004, 10:3317-3326

54. Meeker AK, Argani P: Telomere shortening occurs early during breast tumorigenesis: a cause of chromosome destabilization underlying malignant transformation? J Mammary Gland Biol Neoplasia 2004, 9:285-296

55. Kawai T, Hiroi S, Nakanishi K, Meeker AK: Telomere length and telomerase expression in atypical adenomatous hyperplasia and small bronchioloalveolar carcinoma of the lung. Am J Clin Pathol 2007, $127: 254-262$

56. Hansel DE, Meeker AK, Hicks J, De Marzo AM, Lillemoe KD, Schulick R, Hruban RH, Maitra A, Argani P: Telomere length variation in biliary tract metaplasia, dysplasia, and carcinoma. Mod Pathol 2006, 19:772-779

57. Hanahan D, Weinberg RA: The hallmarks of cancer. Cell 2000, 100: $57-70$

58. Collaborative Group on Epidemiological Studies of Ovarian C, Beral V, Doll R, Hermon C, Peto R, Reeves G: Ovarian cancer and oral contraceptives: collaborative reanalysis of data from 45 epidemiological studies including 23,257 women with ovarian cancer and 87,303 controls. Lancet 2008, 371:303-314

59. Kobayashi Y, Kashima H, Wu RC, Jung JG, Kuan JC, Gu J, Xuan J, Sokoll L, Visvanathan K, Shih IM, Wang TL: Mevalonate pathway antagonist inhibits proliferation of serous tubal intraepithelial carcinoma and ovarian carcinoma in mouse models. Clin Cancer Res 2015, 21:4625-4662

60. Wu NY, Fang C, Huang HS, Wang J, Chu TY: Natural history of ovarian high-grade serous carcinoma from time effects of ovulation inhibition and progesterone clearance of p53-defective lesions. Mod Pathol 2020, 33:29-37

61. Chen LY, Huang RL, Chan MW, Yan PS, Huang TS, Wu RC, Suryo Rahmanto Y, Su PH, Weng YC, Chou JL, Chao TK, Wang YC, Shih IM, Lai HC: TET1 reprograms the epithelial ovarian cancer epigenome and reveals casein kinase 2 alpha as a therapeutic target. J Pathol 2019, 248:363-376

62. Pisanic TR 2nd, Asaka S, Lin SF, Yen TT, Sun H, BahadirliTalbott A, Wang TH, Burns KH, Wang TL, Shih IM: Long interspersed nuclear element 1 retrotransposons become deregulated during the development of ovarian cancer precursor lesions. Am J Pathol 2019, 189:513-520

63. Kim J, Park EY, Kim O, Schilder JM, Coffey DM, Cho CH, Bast RC Jr: Cell origins of high-grade serous ovarian cancer. Cancers (Basel) 2018, 10:433

64. Dehari R, Kurman RJ, Logani S, Shih IM: The development of highgrade serous carcinoma from atypical proliferative (borderline) serous tumors and low-grade micropapillary serous carcinoma: a morphologic and molecular genetic analysis. Am J Surg Pathol 2007 31:1007-1012

65. Murali R, Selenica P, Brown DN, Cheetham RK, Chandramohan R, Claros NL, Bouvier N, Cheng DT, Soslow RA, Weigelt B, McCluggage WG: Somatic genetic alterations in synchronous and metachronous low-grade serous tumours and high-grade carcinomas of the adnexa. Histopathology 2019, 74:638-650

66. Garg K, Park KJ, Soslow RA: Low-grade serous neoplasms of the ovary with transformation to high-grade carcinomas: a report of 3 cases. Int J Gynecol Pathol 2012, 31:423-428

67. Chui MH, Xing D, Zeppernick F, Wang ZQ, Hannibal CG, Frederiksen K, Kjaer SK, Cope L, Kurman RJ, Shih IM, Wang TL, Vang R: Clinicopathologic and molecular features of paired cases of metachronous ovarian serous borderline tumor and subsequent serous carcinoma. Am J Surg Pathol 2019, 43:1462-1472

68. Parker WH, Feskanich D, Broder MS, Chang E, Shoupe D, Farquhar CM, Berek JS, Manson JE: Long-term mortality associated with oophorectomy compared with ovarian conservation in the nurses' health study. Obstet Gynecol 2013, 121:709-716

69. Gilks CB, Irving J, Kobel M, Lee C, Singh N, Wilkinson N, McCluggage WG: Incidental nonuterine high-grade serous carcinomas arise in the fallopian tube in most cases: further evidence for the tubal origin of high-grade serous carcinomas. Am J Surg Pathol $2015,39: 357-364$

70. Morrison JC, Blanco LZ Jr, Vang R, Ronnett BM: Incidental serous tubal intraepithelial carcinoma and early invasive serous carcinoma in the nonprophylactic setting: analysis of a case series. Am J Surg Pathol 2015, 39:442-453

71. McAlpine JN, Hanley GE, Woo MM, Tone AA, Rozenberg N, Swenerton KD, Gilks CB, Finlayson SJ, Huntsman DG, Miller DM; Ovarian Cancer Research Program of British C: Opportunistic salpingectomy: uptake, risks, and complications of a regional initiative for ovarian cancer prevention. Am J Obstet Gynecol 2014, 210:471. e1-471.e11

72. Menon U, Gentry-Maharaj A, Hallett R, Ryan A, Burnell M, Sharma A, Lewis S, Davies S, Philpott S, Lopes A, Godfrey K, Oram D, Herod J, Williamson K, Seif MW, Scott I, Mould T, Woolas R, Murdoch J, Dobbs S, Amso NN, Leeson S, Cruickshank D, McGuire A, Campbell S, Fallowfield L, Singh N, Dawnay A, Skates SJ, Parmar M, Jacobs I: Sensitivity and specificity of multimodal and ultrasound screening for ovarian cancer, and stage distribution of detected cancers: results of the prevalence screen of the UK Collaborative Trial of Ovarian Cancer Screening (UKCTOCS). Lancet Oncol 2009, 10:327-340

73. Buys SS, Partridge E, Black A, Johnson CC, Lamerato L, Isaacs C, Reding DJ, Greenlee RT, Yokochi LA, Kessel B, Crawford ED, Church TR, Andriole GL, Weissfeld JL, Fouad MN, Chia D, O'Brien B, Ragard LR, Clapp JD, Rathmell JM, Riley TL, Hartge P, Pinsky PF, Zhu CS, Izmirlian G, Kramer BS, Miller AB, Xu JL, Prorok PC, Gohagan JK, Berg CD: Effect of screening on ovarian cancer mortality: the prostate, lung, colorectal and ovarian (PLCO) cancer screening randomized controlled trial. JAMA 2011, 305 2295-2303

74. Shintaku M, Taniguchi H, Yamamoto Y, Kono F, Sumitomo M: Detection of tumor cells of serous tubal intraepithelial carcinoma (STIC) in cervical smears and rapid development of the ovarian involvement: a case report. Diagn Cytopathol 2018, 46:945-949

75. Kinde I, Bettegowda C, Wang Y, Wu J, Agrawal N, Shih I-M, Kurman R, Dao F, Levine DA, Giuntoli R, Roden R, Eshleman JR, Carvalho JP, Marie SKN, Papadopoulos N, Kinzler KW, Vogelstein B, Diaz LA Jr: Evaluation of DNA from the Papanicolaou test to detect ovarian and endometrial cancers. Sci Transl Med 2013, 5:167ra4

76. Wang Y, Li L, Douville C, Cohen JD, Yen TT, Kinde I, et al: Evaluation of liquid from the Papanicolaou test and other liquid biopsies for the detection of endometrial and ovarian cancers. Sci Transl Med 2018, 10:eaap8793 
77. Moran S, Martinez-Cardus A, Sayols S, Musulen E, Balana C, Estival-Gonzalez A, Moutinho C, Heyn H, Diaz-Lagares A, de Moura MC, Stella GM, Comoglio PM, Ruiz-Miro M, Matias-Guiu X, Pazo-Cid R, Anton A, Lopez-Lopez R, Soler G, Longo F, Guerra I, Fernandez S, Assenov Y, Plass C, Morales R, Carles J, Bowtell D, Mileshkin L, Sia D, Tothill R, Tabernero J, Llovet JM, Esteller M: Epigenetic profiling to classify cancer of unknown primary: a multicentre, retrospective analysis. Lancet Oncol 2016, 17:1386-1395

78. Ishak CA, Lheureux S, De Carvalho DD: DNA methylation as a robust classifier of epithelial ovarian cancer. Clin Cancer Res 2019, 25:5729-5731

79. Shih IeM, Chen L, Wang CC, Gu J, Davidson B, Cope L, Kurman RJ, Xuan J, Wang TL: Distinct DNA methylation profiles in ovarian serous neoplasms and their implications in ovarian carcinogenesis. Am J Obstet Gynecol 2010, 203:584 e1-22

80. Costello JF, Fruhwald MC, Smiraglia DJ, Rush LJ, Robertson GP, Gao X, Wright FA, Feramisco JD, Peltomaki P, Lang JC, Schuller DE, Yu L, Bloomfield CD, Caligiuri MA, Yates A, Nishikawa R, Su Huang H, Petrelli NJ, Zhang X, O'Dorisio MS, Held WA, Cavenee WK, Plass C: Aberrant CpG-island methylation has non-random and tumour-type-specific patterns. Nat Genet 2000, $24: 132-138$

81. Hulbert A, Jusue-Torres I, Stark A, Chen C, Rodgers K, Lee B, Griffin C, Yang A, Huang P, Wrangle J, Belinsky SA, Wang TH, Yang SC, Baylin SB, Brock MV, Herman JG: Early detection of lung cancer using DNA promoter hypermethylation in plasma and sputum. Clin Cancer Res 2017, 23:1998-2005

82. Bijron JG, Seldenrijk CA, Zweemer RP, Lange JG, Verheijen RH, van Diest PJ: Fallopian tube intraluminal tumor spread from noninvasive precursor lesions: a novel metastatic route in early pelvic carcinogenesis. Am J Surg Pathol 2013, 37:1123-1130

83. Domchek SM, Friebel TM, Singer CF, Evans DG, Lynch HT, Isaacs C, Garber JE, Neuhausen SL, Matloff E, Eeles R, Pichert G, Van t'veer L, Tung N, Weitzel JN, Couch FJ, Rubinstein WS, Ganz PA, Daly MB, Olopade OI, Tomlinson G, Schildkraut J, Blum JL, Rebbeck TR: Association of risk-reducing surgery in BRCA1 or BRCA2 mutation carriers with cancer risk and mortality. JAMA 2010, 304:967-975
84. Finch A, Metcalfe K, Lui J, Springate C, Demsky R, Armel S, Rosen B, Murphy J, Elit L, Sun P, Narod S: Breast and ovarian cancer risk perception after prophylactic salpingo-oophorectomy due to an inherited mutation in the BRCA1 or BRCA2 gene. Clin Genet 2009, $75: 220-224$

85. Chay WY, McCluggage WG, Lee CH, Kobel M, Irving J, Millar J, Gilks CB, Tinker AV: Outcomes of incidental fallopian tube highgrade serous carcinoma and serous tubal intraepithelial carcinoma in women at low risk of hereditary breast and ovarian cancer. Int $\mathrm{J}$ Gynecol Cancer 2016, 26:431-436

86. Powell CB, Swisher EM, Cass I, McLennan J, Norquist B, Garcia RL, Lester J, Karlan BY, Chen L: Long term follow up of BRCA1 and BRCA2 mutation carriers with unsuspected neoplasia identified at risk reducing salpingo-oophorectomy. Gynecol Oncol 2013, 129:364-371

87. Wethington SL, Park KJ, Soslow RA, Kauff ND, Brown CL, Dao F, Otegbeye E, Sonoda Y, Abu-Rustum NR, Barakat RR, Levine DA, Gardner GJ: Clinical outcome of isolated serous tubal intraepithelial carcinomas (STIC). Int J Gynecol Cancer 2013, 23:1603-1611

88. Visvanathan K, Vang R, Shaw P, Gross A, Soslow R, Parkash V, Shih IeM, Kurman RJ: Diagnosis of serous tubal intraepithelial carcinoma based on morphologic and immunohistochemical features: a reproducibility study. Am J Surg Pathol 2011, 35:1766-1775

89. Steenbeek MP, Bulten J, Snijders M, Lombaers M, Hendriks J, van den Brand M, Kraayenbrink AA, Massuger L, Sweegers S, de Hullu JA, Pijnenborg JMA, Kusters-Vandevelde HVN, Reijnen C: Fallopian tube abnormalities in uterine serous carcinoma. Gynecol Oncol 2020, 158:339-346

90. Kommoss F, Faruqi A, Gilks CB, Lamshang Leen S, Singh N, Wilkinson N, McCluggage WG: Uterine serous carcinomas frequently metastasize to the fallopian tube and can mimic serous tubal intraepithelial carcinoma. Am J Surg Pathol 2017, 41:161-170

91. Singh R, Cho KR: Serous tubal intraepithelial carcinoma or not? Metastases to fallopian tube mucosa can masquerade as in situ lesions. Arch Pathol Lab Med 2017, 141:1313-1315

92. McDaniel AS, Stall JN, Hovelson DH, Cani AK, Liu CJ, Tomlins SA, Cho KR: Next-generation sequencing of tubal intraepithelial carcinomas. JAMA Oncol 2015, 1:1128-1132 